\title{
Differential expression of genes involved in entomopathogenicity of the fungi Metarhizium anisopliae var. anisopliae and M. anisopliae var. acridum (Clavicipitaceae)
}

\author{
M.P. Carneiro-Leão ${ }^{1}$, F.D. Andreote ${ }^{2}$, W.L. Araújo ${ }^{3}$ and N.T. Oliveira ${ }^{1}$ \\ ${ }^{1}$ Departamento de Micologia, Universidade Federal de Pernambuco, \\ Recife, PE, Brasil \\ ${ }^{2}$ Departamento de Ciência do Solo, \\ Escola Superior de Agricultura Luiz de Queiroz, Piracicaba, SP, Brasil \\ ${ }^{3}$ Laboratório de Ecologia Microbiana e Biologia Molecular, \\ Universidade de Mogi das Cruzes, Mogi das Cruzes, SP, Brasil \\ Corresponding author: M.P. Carneiro-Leão \\ E-mail: mariele_carneiro@hotmail.com
}

Genet. Mol. Res. 10 (2): 769-778 (2011)

Received October 8, 2010

Accepted December 21, 2010

Published May 3, 2011

DOI 10.4238/vol10-2gmr1094

\begin{abstract}
Expression analysis of the genes involved in germination, conidiogenisis and pathogenesis of Metarhizium anisopliae during its saprophytic and pathogenic life stages can help plan strategies to increase its efficacy as a biological control agent. We quantified relative expression levels of the nitrogen response regulator gene ( $n r r 1)$ and a G-protein regulator of genes involved in conidiogenesis (cag8), using an RT-qPCR assay. Comparisons were made between $M$. anisopliae var. anisopliae and M. anisopliae var. acridum during germination and conidiogenesis and at different stages of pathogenesis. The cag8 gene was repressed during germination and induced during conidial development and the pathogenic phase, and the nrrl gene was induced during germination, conidiogenesis and the pathogenic phase. Both genes were more expressed in M. anisopliae var. anisopliae, demonstrating
\end{abstract}


that different varieties of $M$. anisopliae differ in activation of genes linked to virulence for certain environments and hosts. This suggests that differences among these varieties in the ability to adapt could be attributed not only to specific genomic regions and genes, but also to differential gene expression in this fungus, modulating its ability to respond to environmental stimuli.

Key words: Biocontrol; Entomopathogenic fungi; Quantitative RT-PCR; Pathogenicity gene

\section{INTRODUCTION}

The entomopathogenic fungus Metarhizium anisopliae can infect ca. 200 species from more than 50 insect families (Roberts and Humber, 1981), and is used globally as a biological control agent for many insect pests. Its advantages over chemical pesticides include high insect specificity, low toxicity to other organisms and low environmental impact (Miller et al., 1983). In addition, due to its multiple development processes of infection, insect resistance to $M$. anisopliae is less likely or develops more slowly than resistance to chemical pesticides (He and Xia, 2009). However, its use has been limited due to its relatively slow rate of killing when compared to chemical pesticides (St Leger et al., 1996).

Metarhizium anisopliae is a saprophytic organism with both soil-dwelling and pathogenic life stages (Roberts and Humber, 1981). The morphological, cytological and biochemical mechanisms involved in these two life stages are relatively well understood. However, attempts to improve the effectiveness of entomopathogenic fungi also require a clear understanding of molecular basis (Wang et al., 2005; Wang and St Leger, 2007). In particular, the molecular steps involved in attachment to the host and the penetration of the cuticle are crucial in the establishment of infection and are very attractive in scientific terms (Roberts and Humber, 1981; Wang et al., 2008). Several genes of M. anisopliae implicated in pathogenesis and other developmental stages have been cloned and characterized (St Leger et al., 1992a,b; Bogo et al., 1998; Joshi and St Leger, 1999; Screen et al., 2001; Baratto et al., 2006; He and Xia, 2009). Hence, a detailed study on the timing of the expression of these genes is crucial for elucidating their contribution in the adaptation of the fungus as saprophyte and pathogen.

Here, we show that the genes cag8 (regulator of G-protein signaling) and nrr 1 (regulator of nitrogen) are differentially expressed in M. anisopliae var. anisopliae and M. anisopliae var. acridum during germination, conidiogenesis and pathogenesis. It is likely that this difference in expression allows $M$. anisopliae to respond flexibly to adverse conditions and adapt to different environments and hosts.

\section{MATERIAL AND METHODS}

\section{Biological material}

Metarhizium anisopliae var. anisopliae URM 4921, isolated from Mahanarva posticata, and M. anisopliae var. acridum URM 4412, isolated from Austracnis guttulosa, were obtained from the mycological collection of the Department of Mycology, Federal University 
of Pernambuco (URM-UFPE). Cultures were grown on potato dextrose agar at $28^{\circ} \mathrm{C}$ for 12 days in order to obtain conidia.

\section{Preparation of biological material for the study of gene expression during germination}

Conidia were harvested in $0.01 \%$ Tween 80 aqueous solution, and the conidial suspension was filtered through glass wool to remove mycelia. Conidia were then added to YPD broth $\left(0.2 \%\right.$ yeast extract, $1 \%$ peptone, $2 \%$ dextrose) at a concentration of $2 \times 10^{7}$ conidia $/ \mathrm{mL}$. The conidia were collected by centrifugation at $8 \mathrm{~h}$ (ungerminated conidia-before germination), 10,12 and $14 \mathrm{~h}$ (germinating conidia) after inoculation, immediately frozen in liquid nitrogen and maintained for $24 \mathrm{~h}$ at $-80^{\circ} \mathrm{C}$ for subsequent extraction of RNA. Two biological replicates were performed for each time analysis. Conidial germination was monitored microscopically.

\section{Preparation of biological material for the study of gene expression during conidiogenesis}

Conidia were harvested in $0.01 \%$ Tween 80 aqueous solution, and the conidial suspension was filtered through glass wool to remove mycelia. Conidia $\left(2 \times 10^{7}\right.$ conidia $\left./ \mathrm{mL}\right)$ were spread onto cellophane $(0.5 \mu \mathrm{M}$, pore $)$ on YPD agar $(0.2 \%$ yeast extract, $1 \%$ peptone, $2 \%$ dextrose). Scraped from Petri dishes, the mycelia were collected at $24 \mathrm{~h}$ (mycelial growth), 48 $\mathrm{h}$ (conidiophore development), $72 \mathrm{~h}$ (conidiophore with few conidia), and $96 \mathrm{~h}$ (conidiophores with a large number of conidia) after inoculation, immediately frozen in liquid nitrogen and maintained for $24 \mathrm{~h}$ at $-80^{\circ} \mathrm{C}$ for subsequent extraction of RNA. Two biological replicates were performed for each time analyzed. Fungal conidiogenesis was monitored microscopically.

\section{Preparation of biological material for the study of gene expression during pathogenesis}

Third-instar larvae of Diatraea saccharalis (the sugar cane borer) were infected by immersion for $1 \mathrm{~min}$ in a conidial suspension of $2 \times 10^{8}$ conidia $/ \mathrm{mL}$. The insects collected at $20 \mathrm{~h}$ after infection, dead infected insects, insects with few emergent mycelia, insect cadavers mummified with conidia, and uninfected insect were immediately frozen in liquid nitrogen and maintained for $24 \mathrm{~h}$ at $-80^{\circ} \mathrm{C}$ for subsequent extraction of RNA. Two biological replicates were performed for each phase analyzed.

\section{Total RNA isolation and cDNA synthesis}

Total RNA was isolated from conidia, mycelia and insects described above. The frozen samples were ground with liquid nitrogen. For each sample, 100-150 mg powdered sample was placed in a cooled 2-mL tube. RNA samples were extracted with Trizol reagent (Invitrogen) according to manufacturer instructions. RNA was suspended in $50 \mu \mathrm{L}$ DEPCtreated water. Purity of the total RNA extracted was determined based on the 260/280 nM ratio and integrity was checked by electrophoresis on a $1 \%$ agarose gel. Residual DNA was removed by treating RNA with RNase-free DNase I according to manufacturer instructions (Deoxyribonuclease I, Invitrogen). RNA was stored at $-80^{\circ} \mathrm{C}$ until further use. An aliquot of 
$2 \mu \mathrm{g}$ DNAse-treated RNA was transcribed into cDNA using the SuperScript ${ }^{\mathrm{TM}}$ First-Strand $^{2}$ Synthesis System for RT-PCR (Invitrogen) and oligo-dT primers (Invitrogen).

\section{Real-time quantitative polymerase chain reaction (qPCR) analyses}

To obtain qPCR products, the Platinum ${ }^{\circledR}$ SYBR $^{\circledR}$ Green qPCR SuperMix-UDG kit (Invitrogen) was used. Each qPCR mixture of $25 \mu \mathrm{L}$ contained $12.5 \mu \mathrm{L}$ qPCR SuperMix-UDG Kit (Invitrogen), $0.5 \mu \mathrm{L} \mathrm{MgCl}_{2}(50 \mathrm{mM}), 0.1 \mu \mathrm{L}$ each of the forward and reverse primer (at 100 $\mu \mathrm{M})$ (Beoneer), $10.8 \mu \mathrm{L}$ nuclease-free water and $1 \mu \mathrm{L}$ cDNA $(20 \mathrm{ng} / \mathrm{mL}$ cDNA for all genes). The negative controls (with no DNA template) for each primer set were included in each run to ensure that there was no contamination. For each biological repetition, two reaction tubes were used. The reaction was performed with the iCycler system (Bio-rad). qPCR was carried out after a 1.5 -min activation/denaturation step at $95^{\circ} \mathrm{C}$, followed by 40 cycles of $15 \mathrm{~s}$ at $95^{\circ} \mathrm{C}$, $30 \mathrm{~s}$ at $60^{\circ} \mathrm{C}$, and $30 \mathrm{~s}$ at $72^{\circ} \mathrm{C}$. After the PCR amplification, the specificity of primers was checked by melting curve analyses. In all experiments, a melting curve was performed from $72^{\circ}$ to $96^{\circ} \mathrm{C}$ to verify the specificity of amplification, detected by the presence of a unique amplification product. All PCR amplifications were performed in duplicate, and the mean of all these values was used for final analysis.

The reference gene used was the gene try (involved in the biosynthesis of tryptophan) (Fang and Bidochka, 2006). Its choice was based on the constitutive expression of the gene, with highly similar values of quantification cycle $(\mathrm{Cq})$ in all cDNA samples analyzed. The tested genes in this study were cag8 and $n r r 1$ genes, which were investigated during germination, conidiogenesis and insect pathogenesis, in M. anisopliae var. anisopliae and M. anisopliae var. acridum. The methods used for qPCR quantification were based on previously reported studies; gene cag8 (a regulator of G-protein signaling pathway involved in conidiogenesis) (Fang et al., 2007), and gene $n r r 1$ (a nitrogen regulator response gene) (Screen et al., 1998). The primers for these genes and the lengths of amplified PCR products are shown in Table 1.

Table 1. Primer sequences for genes studied, the length of the polymerase chain reaction (PCR) products, GenBank accession No. and PCR efficiency.

\begin{tabular}{lllcc}
\hline Gene & Forward primer (5'-3') & Reverse primer $\left(5^{\prime}-3^{\prime}\right)$ & GenBank accession No. & Length of PCR products (bp) \\
\hline try & TTGCAATGCATGTTTGATGTC & CAAAGAGTGGTATCGAGTTAC & AY245100 & 174 \\
cag8 & AAGCTGATGGCTAGCGATTC & TTGCGGTTGGAACGACTTTG & DQ826044 & 128 \\
nrr 1 & ACTATTGATGAGCGTCGTAAC & TGCGTCGTTGTCCATGAAG & AJ006468 & 222 \\
\hline
\end{tabular}

\section{Relative quantification of gene expression}

Generation of quantitative data by real-time PCR is based on the number of cycles required for optimal amplification fluorescence to reach a specific threshold of detection $(\mathrm{Cq}$ value) (Bustin et al., 2009). The relative expression ratios were calculated by a mathematical model, which included an efficiency correction for real-time PCR efficiency of the individual transcripts (Pfaffl, 2001). Real-time PCR amplification efficiencies (E) were determined for each set of primers with the slope of a linear regression model (Pfaffl, 2001). The cDNA samples were diluted at a range of $50,25,5,1$, and $0.25 \mathrm{ng} / \mathrm{mL}$ and were used as RT-qPCR 
templates. The standard curves were generated by plotting the log cDNA values against $\mathrm{Cq}$ values obtained over the range of dilutions. The slope of the curves was used to determine the reaction efficiency $(\mathrm{E})$ as $\mathrm{E}=10^{-1 / \text { slope }}$.

During germination, the average $\mathrm{Cq}$ value of conidia collected after $8 \mathrm{~h}$ was set as the control treatment and the average Cq value of conidia collected at 10,12 and $14 \mathrm{~h}$ was set as the sample treatment. During conidiogenesis, the average Cq value of mycelia collected over $24 \mathrm{~h}$ was set as the control treatment and the average $\mathrm{Cq}$ value of mycelia collected at 48,72 and $96 \mathrm{~h}$ was set as the sample treatment. During pathogenesis, the average $\mathrm{Cq}$ value of insect $20 \mathrm{~h}$ after infection was set as the control treatment, and the average $\mathrm{Cq}$ value of insect with emergent mycelia from insect cadavers and insect cadavers mummified with conidia was set as the sample treatment.

After the calculation of the $\mathrm{R}$ values from each biological repetition, the relative gene expression levels for M. anisopliae var. anisopliae and M. anisopliae var. acridum were presented as $\log _{2}$ R. In this way, values were directly and numerically correlated with the induction or repression of gene expression, and thus, from the zero level of expression, the genes analyzed could be relatively induced (positive values) or repressed (negative values). Afterwards, the data were subjected to analysis of variance (ANOVA) and means compared by the Tukey test at 5\% probability using the Assistat 7.4 software (Silva and Azevedo, 2002).

\section{RESULTS AND DISCUSSION}

In this study, information was gathered supplying a better understanding of the role of the genes cag8 and nrr1, implied by differential expression during the adaptation of these fungi as saprophyte and pathogen.

According to the standard curve obtained from the slope of the dilutions of each gene evaluated, the PCR efficiency (E) varied from 98 to $108 \%$ and regression coefficient values $\left(\mathrm{R}^{2}\right)$ varied from 0.981 and 0.994 . Analysis of the melting curves showed the specificity of the primers, with unique peaks for the amplifications with each primer set (Table 2). These results support the fidelity in representing the expression of target genes under distinct environmental conditions.

Table 2. $\mathrm{E}$ and $\mathrm{R}^{2}$ values of linear regressions for dilutions of the reference and target gene transcripts.

\begin{tabular}{lcc}
\hline Gene & E value (\%) & $\mathrm{R}^{2}$ value \\
\hline cag8 & $98 \%$ & 0.994 \\
nnr 1 & $105.4 \%$ & 0.994 \\
try & $108 \%$ & 0.981 \\
\hline
\end{tabular}

$\mathrm{E}=$ efficiency value: $\mathrm{R}^{2}=$ regression coefficient value.

The gene cag8 acts in regulating the G-protein signaling pathways on the conidial surface, and thus it is involved in the interaction with the lipid layer on the surface of the host, promoting the adhesion of conidia on the insect cuticle through hydrophobic mechanisms (Boucias et al., 1988; Hamm, 1998). In M. anisopliae, this gene also plays a role in the regulation of conidiation, virulence and hydrophobin synthesis (Fang et al., 2007). Corroborating these findings, we observed the differential expression of this gene in both M. anisopliae var. 
anisopliae and M. anisopliae var. acridum during germination, conidiogenesis and pathogenesis. After 10, 12 and $14 \mathrm{~h}$ of germination, the expression of the cag8 gene was differentially repressed when compared with $8 \mathrm{~h}$ (ungerminated conidia) in M. anisopliae var. anisopliae and M. anisopliae var. acridum. In M. anisopliae var. anisopliae a significant difference was observed only after $14 \mathrm{~h}$, whereas in M. anisopliae var. acridum the expression was differentially repressed at all times examined (Figure 1).

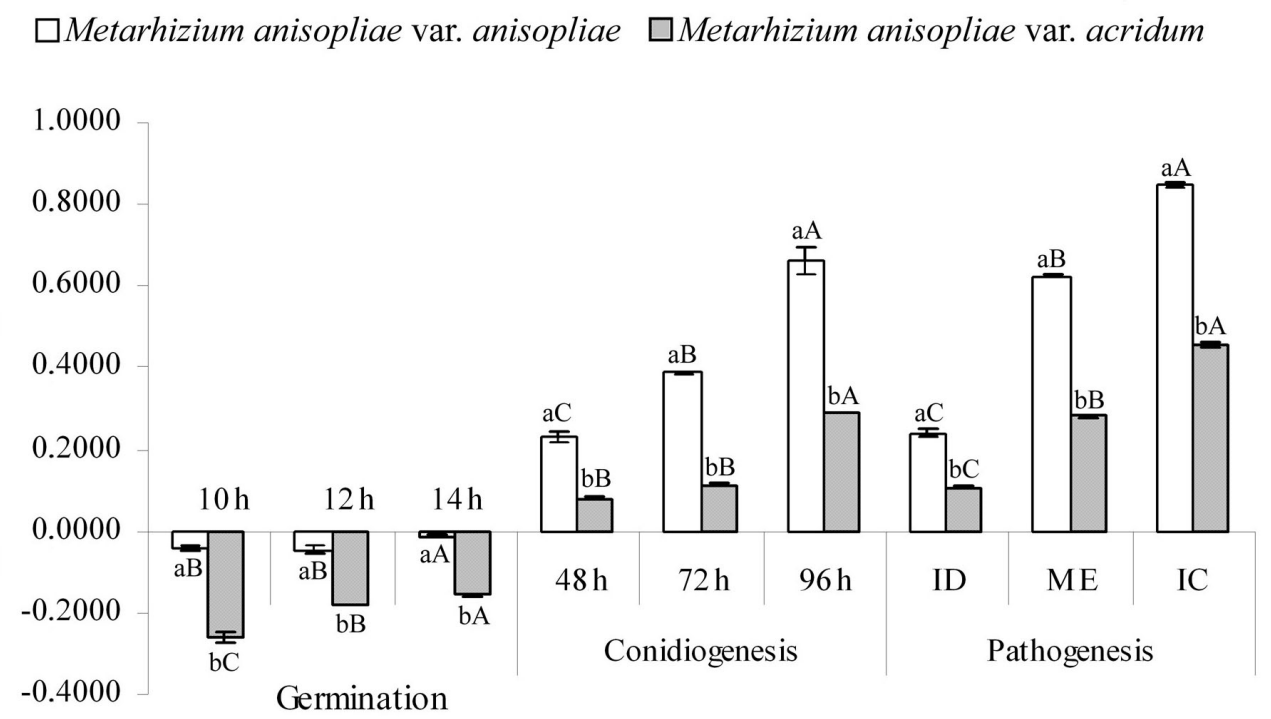

Figure 1. Relative expression levels of cag8 during germination, conidiogenesis and pathogenesis of Metarhizium anisopliae var. anisopliae and $M$. anisopliae var. acridum. ID = dead infected insect; $\mathrm{ME}=$ emergent mycelia from insect cadavers; IC = insect cadavers completely covered with conidia. Means followed by distinct letters differ by the Tukey test at $5 \%$ probability; lowercase letters represent differences between isolates at each time of culture, and uppercase letters represent the differences between times for each isolate.

Differences were also found in this gene expression during conidiogenesis. After 48, 72 and $96 \mathrm{~h}$ of conidiogenesis, cag8 was induced when compared to $24 \mathrm{~h}$ (mycelial growth) in both varieties. In M. anisopliae var. anisopliae, significant differences were observed at all times examined. However, in $M$. anisopliae var. acridum a statistical difference was observed only at $96 \mathrm{~h}$. When comparing the two varieties, there were significant differences, with a greater induction in M. anisopliae var. anisopliae (Figure 1).

During the stages of pathogenesis, both M. anisopliae var. anisopliae and M. anisopliae var. acridum showed significantly different levels of induction when compared to those $20 \mathrm{~h}$ after infection, with a similar trend as observed during conidiogenesis. In both varieties, greater induction was observed in insects covered with conidia (conidiogenesis stage) and lower in the dead insect. When comparing the two varieties, M. anisopliae var. anisopliae showed higher induction (Figure 1).

The repression of this gene during germination and induction in conidiogenesis, as well as in the conidiogenesis stages of pathogenesis, reinforce the association between cag8 and conidiogenesis. The conidium is the propagation structure that is involved in disease 
transmission (Fang et al., 2007). Thus, an understanding in the level of gene expression involved in conidiogenesis is an important step to the commercial development and improvement of this biocontrol fungus. Here, we observed that M. anisopliae var. anisopliae showed higher expression of this gene during the process of pathogenesis. Lima (2005) observed that $M$. anisopliae var. anisopliae showed higher potential pathogenicity in D. saccharalis than $M$. anisopliae var. acridum. Fang et al. (2007) analyzed an M. anisopliae cag8 loss-of function mutant strains and observed a decreased virulence in Galleria mellonella. Thus, we suggest that varieties of $M$. anisopliae that have higher expression of this gene may show a higher virulence in accordance with the host.

Another gene analyzed in this study is related to nitrogen processing by the fungi. The fungi have elaborate control mechanisms to provide a constant supply of nitrogen during distinct stages of differentiation, such as during the pathogenesis process. Recent studies have pointed to the fact that even genes encoding regulatory molecules or those that are involved in growth and secretion could also be considered to be pathogenicity related, since they may play important functions during the process of adaptation to the various insect cuticles (Casadevall and Pirofski, 2001; Freimoser et al., 2005; Wang et al., 2005). The nitrogen response regulator gene $n r r 1$ has been shown to be important in the pathogenicity of M. anisopliae (Screen et al., 1998), since several enzymes involved in the penetration of the insect cuticle are also regulated in response to nitrogen availability (St Leger et al., 1997). We observed that $n r r 1$ was constitutively induced at 10,12 and $14 \mathrm{~h}$ of germination when compared to $8 \mathrm{~h}$ (ungerminated conidia), at 48,72 and $96 \mathrm{~h}$ of conidiogenesis when compared to $24 \mathrm{~h}$ (mycelial growth) and during the stages of pathogenesis when compared to the insect at $20 \mathrm{~h}$ after infection. However, no interaction was observed between varieties and time for germination $(\mathrm{F}=4.3607, \mathrm{P}=0.0677)$, conidiogenesis $(\mathrm{F}=3.3102, \mathrm{P}>0.10000)$ and pathogenesis $(\mathrm{F}=1.166, \mathrm{P}>0.10000)$ (Figure 2).

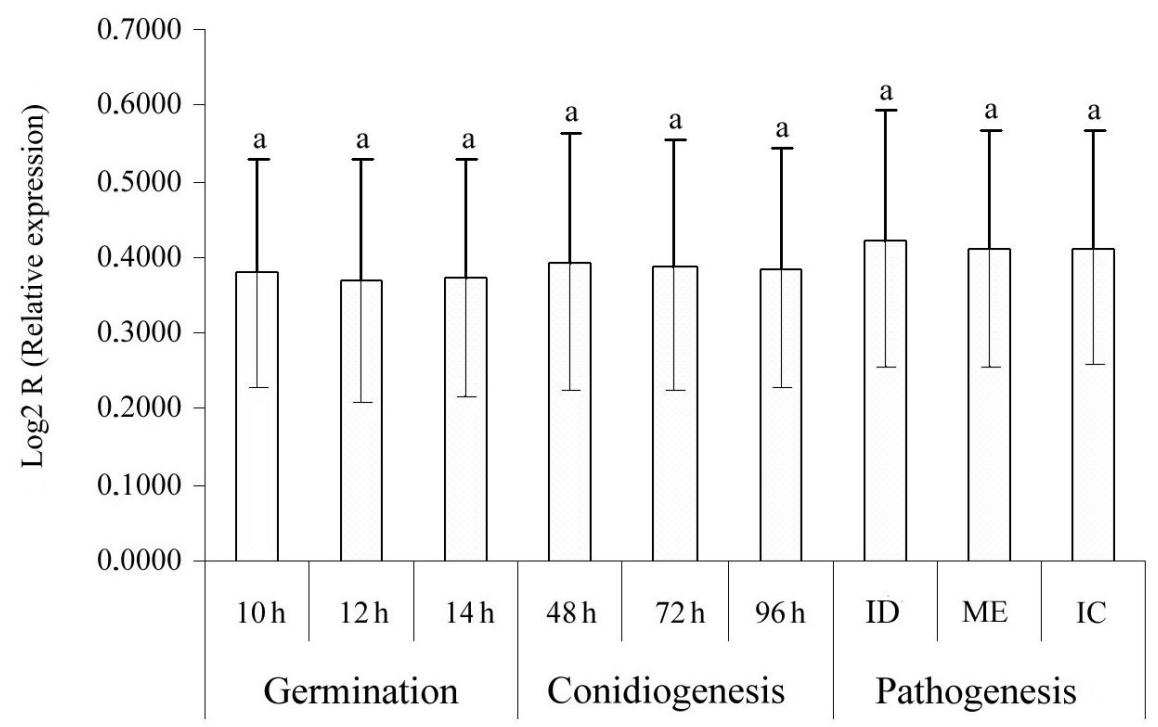

Figure 2. Relative expression levels of $n r r 1$ during germination, conidiogenesis and pathogenesis. ID $=$ dead infected insect; $\mathrm{ME}=$ emergent mycelia from insect cadavers; IC = insect cadavers completely covered with conidia. Means followed by distinct letters differ by the Tukey test at $5 \%$ probability. 
Significant differences were observed for the three developmental stages only when analyzing the two varieties, with a higher expression in $M$. anisopliae var. anisopliae (Figure 3 ), which may be related to its high virulence against $D$. sacchacalis, since the synthesis of enzymes involved in the penetration of $M$. anisopliae in arthropods is regulated in response to nitrogen availability. The consistent expression of these genes on YPD broth or agar and in insects suggests that this gene may mediate nitrogen catabolite depression. Fang and Bidocchka (2006) also observed constitutive expression of this gene during germination, spore production and pathogenesis of M. anisopliae.

Metarhizium anisopliae var. anisopliae

$\square$ Metarhizium anisopliae var. acridum

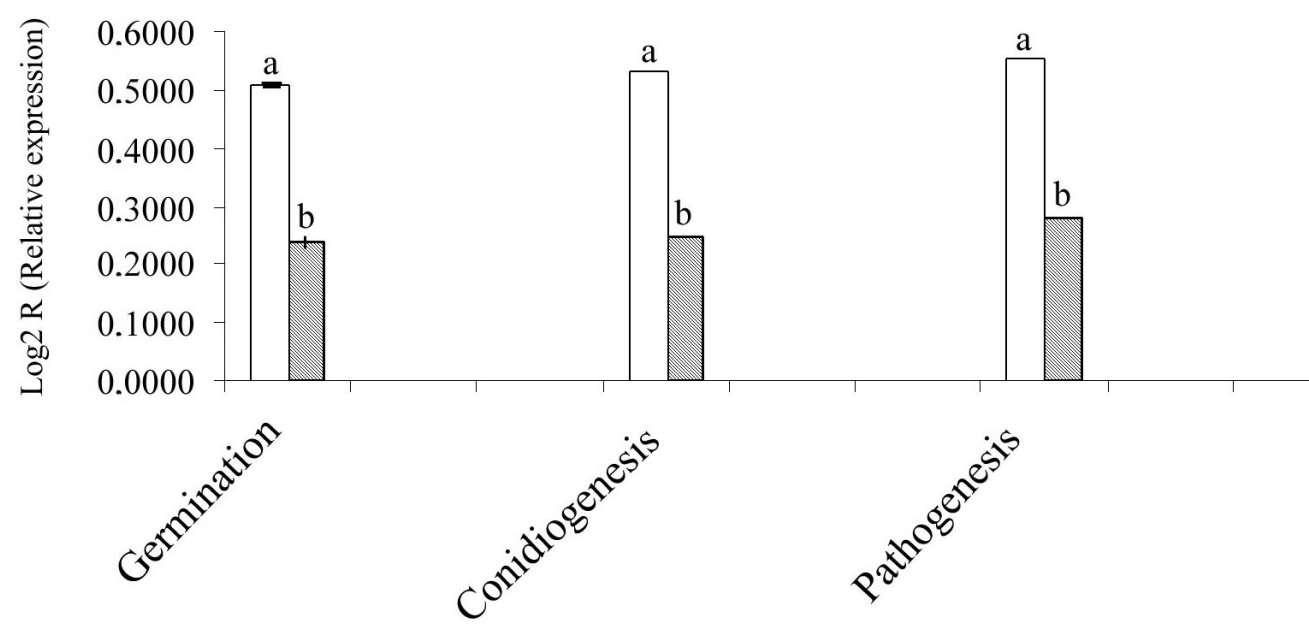

Figue 3. Relative expression levels of nrr 1 during germination, conidiogenesis and pathogenesis of Metarhizium anisopliae var. anisopliae and M. anisopliae var. acridum independent of time. Means followed by distinct letters differ by the Tukey test at $5 \%$ probability.

M. anisopliae var. anisopliae and M. anisopliae var. acridum are facultative saprophytes with both free-living (saprophytic) and pathogenic life stages. However, M. anisopliae var. anisopliae is a cosmopolitan pathogen and has been reported from over 200 insect species (Samuels et al., 1989). In contrast, M. anisopliae var. acridum is less plastic in its physiological responses and has a very limited host range (Inglis et al., 2001). Thus, a better estimate of the range of $M$. anisopliae pathogenicity determinants may be obtained by studying both subspecies (St Leger et al., 1988, 1992b, 1996; Freimoser et al., 2003). This exhibited plasticity could be attributed not only to the presence of specific genomic regions and genes, but also to the differential gene expression in this fungus, modulating its ability to respond to environmental stimuli. Identifying genes that are up- or down-regulated in the fungus in response to a given host insect or growth condition certainly contributes to the knowledge of the genetic mechanisms involved in host specificity and adaptation (Pathan et al., 2007). Corroborating these findings, our results showed clear differences in the expression of the genes analyzed during germination, conidiogenesis and pathogenesis between M. anisopliae var. anisopliae 
and M. anisopliae var. acridum, i.e., higher expression of the genes cag8 and $n r r 1$ in $M$. anisopliae var. anisopliae. Additionally, it was also remarkable that these varieties use different strategies to infect diverse groups of insects and adapt to different environments. This knowledge of differential gene expression helps to elucidate the molecular mechanisms associated with the metabolic versatility of $M$. anisopliae, representing an important tool for programs of genetic improvement of strains used in the biological control of pests.

\section{ACKNOWLEDGMENTS}

We would like to thank Dr. David Bousfield for critically reading this manuscript. Research supported by the Conselho Nacional de Desenvolvimento Científico e Tecnológico $(\mathrm{CNPq})$.

\section{REFERENCES}

Baratto CM, Dutra V, Boldo JT, Leiria LB, et al. (2006). Isolation, characterization, and transcriptional analysis of the chitinase chi2 Gene (DQ011663) from the biocontrol fungus Metarhizium anisopliae var. anisopliae. Curr. Microbiol. 53: 217-221.

Bogo MR, Rota CA, Pinto H Jr, Ocampos M, et al. (1998). A chitinase encoding gene (chit1 gene) from the entomopathogen Metarhizium anisopliae: isolation and characterization of genomic and full-length cDNA. Curr. Microbiol. 37: 221225.

Boucias DG, Pendland JC and Latge JP (1988). Nonspecific factors involved in attachment of entomopathogenic deuteromycetes to host insect cuticle. Appl. Environ. Microbiol. 54: 1795-1805.

Bustin SA, Benes V, Garson JA, Hellemans J, et al. (2009). The MIQE guidelines: minimum information for publication of quantitative real-time PCR experiments. Clin. Chem. 55: 611-622.

Casadevall A and Pirofski L (2001). Host-pathogen interactions: the attributes of virulence. J. Infect. Dis. 184: 337-344.

Fang W and Bidochka MJ (2006). Expression of genes involved in germination, conidiogenesis and pathogenesis in Metarhizium anisopliae using quantitative real-time RT-PCR. Mycol. Res. 110: 1165-1171.

Fang W, Pei Y and Bidochka MJ (2007). A regulator of a G protein signalling (RGS) gene, cag8, from the insect-pathogenic fungus Metarhizium anisopliae is involved in conidiation, virulence and hydrophobin synthesis. Microbiology 153: 1017-1025.

Freimoser FM, Screen S, Bagga S, Hu G, et al. (2003). Expressed sequence tag (EST) analysis of two subspecies of Metarhizium anisopliae reveals a plethora of secreted proteins with potential activity in insect hosts. Microbiology 149: 239-247.

Freimoser FM, Hu G and St Leger RJ (2005). Variation in gene expression patterns as the insect pathogen Metarhizium anisopliae adapts to different host cuticles or nutrient deprivation in vitro. Microbiology 151:361-371.

Hamm HE (1998). The many faces of G protein signaling. J. Biol. Chem. 273: 669-672.

He M and Xia Y (2009). Construction and analysis of a normalized cDNA library from Metarhizium anisopliae var. acridum germinating and differentiating on Locusta migratoria wings. FEMS Microbiol. Lett. 291: 127-135.

Inglis GD, Goettel MS, Butt TM and Strasser H (2001). Fungi as Biocontrol Agents. In: Use of Hyphomycetous Fungi for Managing Insect Pests (Butt TM, Jackson C and Magan N, eds.). CAB International, Wallingford, 23-69.

Joshi L and St Leger RJ (1999). Cloning, expression, and substrate specificity of MeCPA, a zinc carboxypeptidase that is secreted into infected tissues by the fungal entomopathogen Metarhizium anisopliae. J. Biol. Chem. 274: 9803-9811.

Lima MLF (2005). Caracterização Molecular de Espécies de Metarhizium e Patogenicidade sobre Diatraea saccharalis. Doctoral thesis, Universidade Federal de Pernambuco, Recife.

Miller LK, Lingg AJ and Bulla LA Jr (1983). Bacterial, viral, and fungal insecticides. Science 219: 715-721.

Pathan AA, Uma DK, Vogel H and Reineke A (2007). Analysis of differential gene expression in the generalist entomopathogenic fungus Beauveria bassiana (Bals.) Vuillemin grown on different insect cuticular extracts and synthetic medium through cDNA-AFLPs. Fungal Genet. Biol. 44: 1231-1241.

Pfaffl MW (2001). A new mathematical model for relative quantification in real-time RT-PCR. Nucleic Acids Res. 29: e45.

Roberts DW and Humber RA (1981). Entomogenous Fungi. In: Biology of Conidial Fungi (Cole GT and Kendrick B, eds.). Academic Press, New York, 201-236. 
Samuels KDZ, Pinnock DE and Allsopp PG (1989). The potential of Metarhizium anisopliae (Metschnikoff) Sorokin (Deutermycotina, Hyphomycetes) as a biological control-agent of Inopus rubriceps (Macquart) (Diptera, Stratiomyidae). J. Aust. Entomol. Soc. 28: 69-74.

Screen S, Bailey A, Charnley K, Cooper R, et al. (1998). Isolation of a nitrogen response regulator gene (nrr1) from Metarhizium anisopliae. Gene 221: 17-24.

Screen SE, Hu G and St Leger RJ (2001). Transformants of Metarhizium anisopliae sf. anisopliae overexpressing chitinase from Metarhizium anisopliae sf. acridum show early induction of native chitinase but are not altered in pathogenicity to Manduca sexta. J. Invertebr. Pathol. 78: 260-266.

Silva FAS and Azevedo CAV (2002). Assistant computational program version for the windows operating system. Braz. J. Agro-Industrial Prod. 4: 71-78.

St Leger RJ, Durrands PK, Cooper RM and Charnley AK (1988). Regulation of production of proteolytic enzymes by the entomopathogenic fungus Metarhizium anisopliae. Arch. Microbiol. 150: 413-416.

St Leger RJ, Frank DC, Roberts DW and Staples RC (1992a). Molecular cloning and regulatory analysis of the cuticledegrading-protease structural gene from the entomopathogenic fungus Metarhizium anisopliae. Eur. J. Biochem. 204: 991-1001.

St Leger RJ, Staples RC and Roberts DW (1992b). Cloning and regulatory analysis of starvation-stress gene, ssgA, encoding a hydrophobin-like protein from the entomopathogenic fungus, Metarhizium anisopliae. Gene 120: 119124.

St Leger RJ, Joshi L, Bidochka MJ and Roberts DW (1996). Construction of an improved mycoinsecticide overexpressing a toxic protease. Proc. Natl. Acad. Sci. U. S. A. 93: 6349-6354.

St Leger RJ, Joshi L and Roberts DW (1997). Adaptation of proteases and carbohydrases of saprophytic, phytopathogenic and entomopathogenic fungi to the requirements of their ecological niches. Microbiology 143: 1983-1992.

Wang C and St Leger RJ (2007). The MAD1 adhesin of Metarhizium anisopliae links adhesion with blastospore production and virulence to insects, and the MAD2 adhesin enables attachment to plants. Eukaryot. Cell 6: 808-816.

Wang C, Gan H and St Leger RJ (2005). Differential gene expression by Metarhizium anisopliae growing in root exudate and host (Manduca sexta) cuticle or hemolymph reveals mechanisms of physiological adaptation. Fungal Genet. Biol. 42: 704-718.

Wang C, Duan Z and St Leger RJ (2008). MOS1 osmosensor of Metarhizium anisopliae is required for adaptation to insect host hemolymph. Eukaryot. Cell 7: 302-309. 